\title{
LUT
}

Lappeenranta

University of Technology

\section{Challenges related to solute analysis of bauxite residue filter cakes}

Kinnarinen Teemu, Huhtanen Mikko, Holliday Lloyd, Häkkinen Antti

This is a Final draft version of a publication

published by Elsevier

in Minerals Engineering

DOI: $\quad 10.1016 /$ j.mineng.2018.02.001

Copyright of the original publication: (c) Elsevier 2018

Please cite the publication as follows:

Kinnarinen, T., Huhtanen, M., Holliday, L., Häkkinen, A., Challenges related to solute analysis of bauxite residue filter cakes, Minerals Engineering, 2018, 120: 1-6. DOI: 10.1016/j. mineng.2018.02.001 


\title{
Challenges related to solute analysis of bauxite residue filter cakes
}

\author{
Teemu Kinnarinen ${ }^{1}$, Mikko Huhtanen ${ }^{1}$, Lloyd Holliday², Antti Häkkinen ${ }^{1}$ \\ ${ }^{a}$ LUT School of Engineering Science, Lappeenranta University of Technology, \\ P.O. Box 20, FI-53851 Lappeenranta, Finland

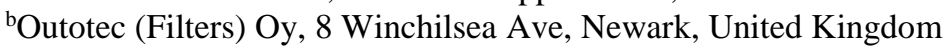

\begin{abstract}
Solute analysis of bauxite residue filter cakes is an important but not very well understood operation carried out at refineries and in scientific research. As more and more refineries rely currently on dry cake disposal after filtration, washing and deliquoring of the cakes, the importance of correctly performed cake analysis will increase. Chemical analysis of bauxite residue filter cakes regarding their soluble compounds, such as the total caustic, soda and aluminate, is performed after forming a slurry from the cake and pure water by using a selected liquid/solid (L/S) ratio. This paper shows that there is currently no cake analysis procedure which could be used without unexpected variation in the results. This is because several factors affect the analysis result at the filtration and sample preparation stages. The factors discussed in this paper are divided into two groups, including the filtration and washing conditions and the sample preparation procedures. In the filtration stage, the filtration temperature and pressure were found to have a considerable effect on the solute recovery. On the other hand, the sample preparation procedure was observed to be affected by factors like the $\mathrm{L} / \mathrm{S}$ ratio, the composition of the diluting liquid (with respect to its $\mathrm{Na}_{2} \mathrm{CO}_{3}$ concentration), the temperature, and the cake leaching time. In addition to the cake solute analysis, particle size measurements and calculation of alkali recovery for the solid-liquid separation stage are discussed as well. To summarize the main findings, it can be stated that significant differences in the results can be seen when any detail in the sample preparation procedure is changed.
\end{abstract}

\section{Introduction}

Bauxite residue is the largest waste fraction generated in the alumina industry. According to the recent online statistics of World Aluminium, the amount of bauxite residue generated annually has increased mainly in China, and the total amount was approximately 150 million tons in 2015 . The total inventory of the residue disposed of during the past decades has been estimated to be over 4 billion tons (Kong et al., 2017) The residue is highly caustic (Clark et al., 2015), has a fine particle size distribution (Johnston et al., 2010; Luo et al., 2016), and it contains a wide variety of metals, including both environmentally problematic metals, such as $\mathrm{Cd}, \mathrm{Cu}, \mathrm{Ni}$ and $\mathrm{Zn}$ (Ghosh et al., 2011) and valuable metals, e.g. Ti, V and rare earths (Liu and Li, 2015; Deng et al., 2017). Bauxite residue has a high buffering capacity, which is largely associated with its alkaline solids content, e.g. a variety of hydroxides, carbonates, aluminates and aluminosilicates (Gräfe et al., 2011).

The disposal of bauxite residue in the form of filter cakes, i.e. dry cake disposal, is an emerging method, which enables disposal of the residue in landfills, instead of lagooning (Power et al., 2011). The total solids concentration of filtered and washed bauxite residue cakes is typically over $70 \mathrm{wt}$. \% when filter presses or hyperbaric drum filters are used (Kinnarinen et al., 2015c; Bott and Langeloh, 2015). As the environmental regulations are becoming stricter in most countries, the need for better understanding of cake analysis procedures is increasing. Due to the recovery of the caustic liquor from the cake in the filtration plant, the cakes are prone to a decrease of $\mathrm{pH}$ when the samples are prepared for the analysis of solutes by forming 
slurries with water. The solutes of interest are the total alkali, total caustic, sodium and alumina. All these species may leach out from the suspended solids when the cake samples are mixed with water to form suspensions for analyzing the solute concentrations, for instance by titration, atomic absorption spectrometry (AAS), or inductively coupled plasma mass spectrometry (ICP-MS). However, the influence of the sample preparation conditions on the analysis result has not been summarized in the existing literature.

The objective of this article is to initiate discussion on the factors affecting the analysis results of bauxite residue filter cakes. One of the most important long-term objectives of the paper is to disclose the need for developing a universal, reliable and comparable procedure for the solute analysis of bauxite residue cakes. The paper summarizes the most important findings of the authors, obtained during several years of filtration research with a large number of different bauxite residues. The aim is to demonstrate, mainly by using dimensionless values, that the analysis results are highly sensitive to a number of factors in each stage of sample preparation.

\section{Materials and methods}

Industrial bauxite residue samples from most continents were used as raw materials in the studies. The cakes were obtained either directly from refineries or as a result of filtration and cake washing experiments performed at Outotec Filters and Lappeenranta University of Technology, both located in Lappeenranta, Finland.

\subsection{Effect of filtration and washing conditions}

The first part of the study was targeted at illustrating the effect of process temperature and pressure on the leaching out of solutes from bauxite residue filter cakes. The study was performed by using two different filters, a Nutsche filter $\left(\mathrm{A} \approx 20 \mathrm{~cm}^{2}\right)$ and a Larox PF 0.1 filter press $\left(\mathrm{A}=0.1 \mathrm{~m}^{2}\right)$. Cake washing was performed in both filters at $65{ }^{\circ} \mathrm{C}$ by using moderate wash ratios and water as the washing liquid. Additionally, leaching trials at atmospheric pressure (at 20 and $65^{\circ} \mathrm{C}$ ) were carried out by using the same bauxite residue slurry that was used in the filtration experiments. The results of the studies on the effect of pressure and temperature applied in the washing and solid-liquid separation stage have been presented earlier in a different form by Kinnarinen et al. (2015b). For comparison, dilution of different bauxite residue slurries with water has also been investigated by Kinnarinen et al. (2015a).

\subsection{Effect of sample preparation procedure}

The effect of the L/S ratio in the sample preparation stage was studied by using a washed and homogenized filter cake with a total solids content of $78 \mathrm{wt} . \%$. In this case, the cake was obtained directly from an alumina refinery. The cake samples were reslurried and mixed with a VWR orbital shaker at the speed of $250 \mathrm{rpm}$. A wide range of weight-based liquid/solid (L/S) ratios from 1 to 49 was used. The L/S ratios can be converted to wt.\% according to Eq. (4). The experiments were performed at room temperature, and the samples were let to stabilize for 2 days before performing solute analyses for the clarified supernatant.

The influence of the composition of the dilution liquid was evaluated by using the same cake material as above in the L/S ratio -related investigations. The aim of this series of experiments was to study if it is possible to avoid desorption and dissolution of the suspended solids content of the cake by using a $\mathrm{Na}_{2} \mathrm{CO}_{3}$ solution with different concentrations in the cake reslurrying procedure, instead of using pure water. The

$\mathrm{Na}_{2} \mathrm{CO}_{3}$ concentrations of the dilution liquids in these experiments were $25.5,51.0$ and $76.9 \mathrm{~g} / \mathrm{kg}$, and the 
temperatures were 20,50 and $80{ }^{\circ} \mathrm{C}$. Additionally, control experiments were performed for comparison, using pure water and the same temperatures.

When a bauxite residue filter cake is suspended in water, the resulting reactions never take place immediately. To demonstrate the importance of the sample stabilization time in the analysis of the cake, experiments were performed by using short and long stabilization times ( $75 \mathrm{~s}$ and $2 \mathrm{~d}$ ) and two L/S ratios (1 and 9). For comparison, the effect of the dilution liquid was also studied by using both water and mother liquor, in this case the filtrate, as the dilution liquids. At the end of the stabilization time, the sample was centrifuged at $1700 \mathrm{G}$ with a Jouan GT 422 bucket centrifuge for $2 \mathrm{~min}$. The clear supernatant was separated for analysis immediately after the centrifugation.

The analytical operations were performed with AAS for $\mathrm{Na}$ and $\mathrm{Al}$, and with a thermometric titrator capable of measuring e.g. the total caustic and aluminate. The sodium concentrations were measured with AAS by using a Thermo Scientific iCE 3000 atomic absorption spectrometer. The thermometric titrations were carried out with a Metrohm 859 Titrotherm device, according to Metrohm Application Bulletin 313 e (Determination of total caustic, total soda and alumina in Bayer process liquors with 859 Titrotherm). The total caustic is defined as follows: the total hydroxyl ion content, which comprises the free hydroxyl ion $\left(\mathrm{OH}^{-}\right)$content and one mol OH${ }^{-}$per mol aluminate. Parallel runs were performed regularly with both devices to ensure reliability of the analyses.

The $\mathrm{pH}$ values of the cake sample slurries were measured with a WTW $\mathrm{pH} 340 \mathrm{i} \mathrm{pH}$ meter and a WTW SenTix 41 electrode.

Particle size distributions of a washed filter cake sample were measured at different conditions with a Malvern Mastersizer 3000 laser diffraction particle size analyzer and a Hydro EV particle dispersion unit. The particle size analyses were performed both with and without ultrasonication and without dispersing agents by using the stirring rate of $3500 \mathrm{rpm}$. The Fraunhofer optical model was utilized, and each measurement was performed at least three times. Averaged particle size distributions were then calculated from the data.

\section{Calculations and definitions}

The calculation of caustic recovery in the filtration of bauxite residue and washing of the formed filter cakes can be performed by relying on the solute concentrations of the slurry, wash liquid, filtrates, and the cake, as presented in Fig. 1. 
(B) Solute coming IN

with wash liquid

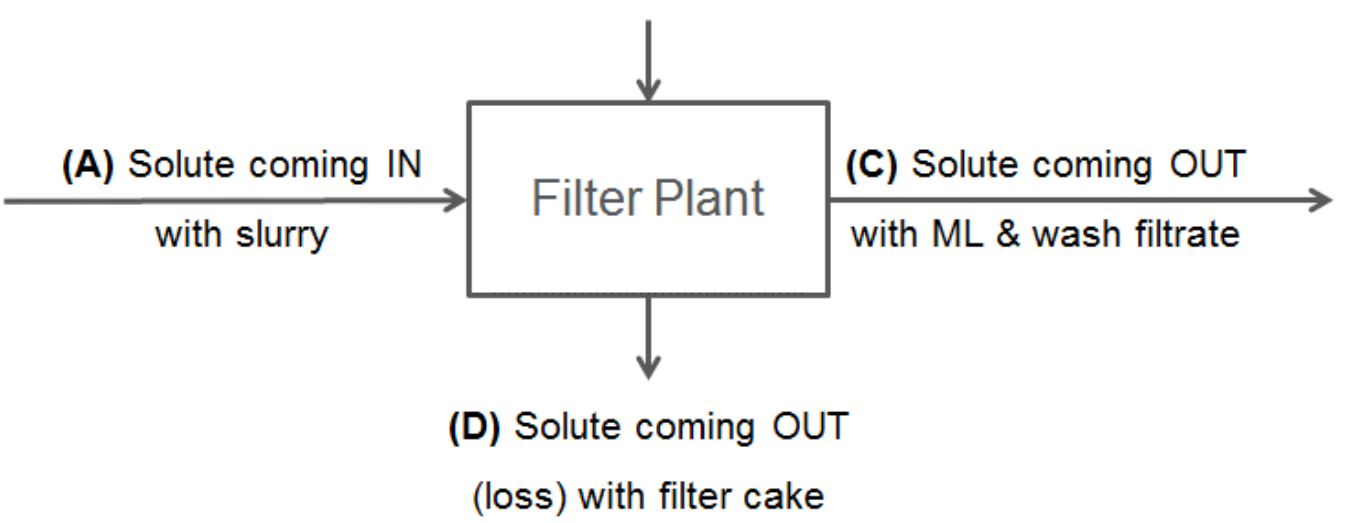

Fig. 1. Material streams A-D used in the mass balance and solute recovery calculations (ML stands for mother liquor).

In this study, the solute recovery is defined in two alternative ways, according to Eqs. (1) and (2) by using the letters A-D introduced in Fig. 1.

Recovery R1 (\%) is based on slurry (A), wash liquid (B) and filtrate (C):

$R 1=\frac{C}{A+B} \cdot 100 \%$

Recovery R2 (\%) is based on slurry (A), wash liquid (B) and cake (D):

$R 2=1-\frac{D}{A+B} \cdot 100 \%$

As can be seen in Eq.(2), the solute recovery R2 is increased as a result of a decrease in the measured solute content of the cake (D). What is often not taken into account is the influence of the sample preparation method on the analysis results. The impacts of some variables are considerable, as will be shown in the Results section of the study. Therefore, the selection of the sample preparation procedure is of crucial importance when the solute recovery is calculated by using the solute contents of the filter cakes.

The $\mathrm{Na}_{2} \mathrm{O}$ surplus (Sections 4.1 and 4.2) is defined as follows:

Surplus $\left(\mathrm{Na}_{2} \mathrm{O}\right)=\left(\frac{m_{\mathrm{Na} 2 \mathrm{O}, \text { filtrate }}}{m_{\mathrm{Na} 2 \mathrm{O}, \mathrm{ML}}}-1\right) \cdot 100 \%$

where the subscript $M L$ means mother liquor and filtrate means either the liquid coming out of a filter or the liquid collected from a cake leaching test. The $\mathrm{Al}_{2} \mathrm{O}_{3}$ surplus (Section 4.2) is defined according to the same principle. 
The solids content $c_{s}(\mathrm{wt}-\%)$ is related to the dimensionless L/S ratio by Eq. (4).

$$
c_{s}=\frac{1}{(L / S \text { ratio })+1} \cdot 100 \%
$$

\section{Results}

A comparison of the washing of the bauxite residue cakes in pressure filters and the washing/leaching of the same material in the form of slurry with water at atmospheric pressure is presented in Section 4.1. An overview of the factors affecting the solute analyses of filter cakes and the calculated values of solute recovery can be found in Sections 4.2 - 4.4. In addition to the solute contents, some interesting observations regarding particle size measurements are presented in Section 4.5.

\subsection{Filtration and slurry dilution: effect of pressure and temperature}

Fig. 2 shows a comparison of the washing conditions of bauxite residue. The filter cakes compacted at pressures of 12 and 6 bar after cake washing at different wash ratios can be observed to release relatively high amounts of sodium from their solid phase. On the other hand, the wash ratios required to reach the same relative surplus of $\mathrm{Na}_{2} \mathrm{O}$ dissolution (Eq. (3)) in the slurry leaching tests at 20 and $65{ }^{\circ} \mathrm{C}$ are much higher. The cake analyses were performed with AAS after reslurrying the cake samples in water (L/S ratio $=9$ ). The analyses were performed after the sample stabilization time of $24 \mathrm{~h}$.

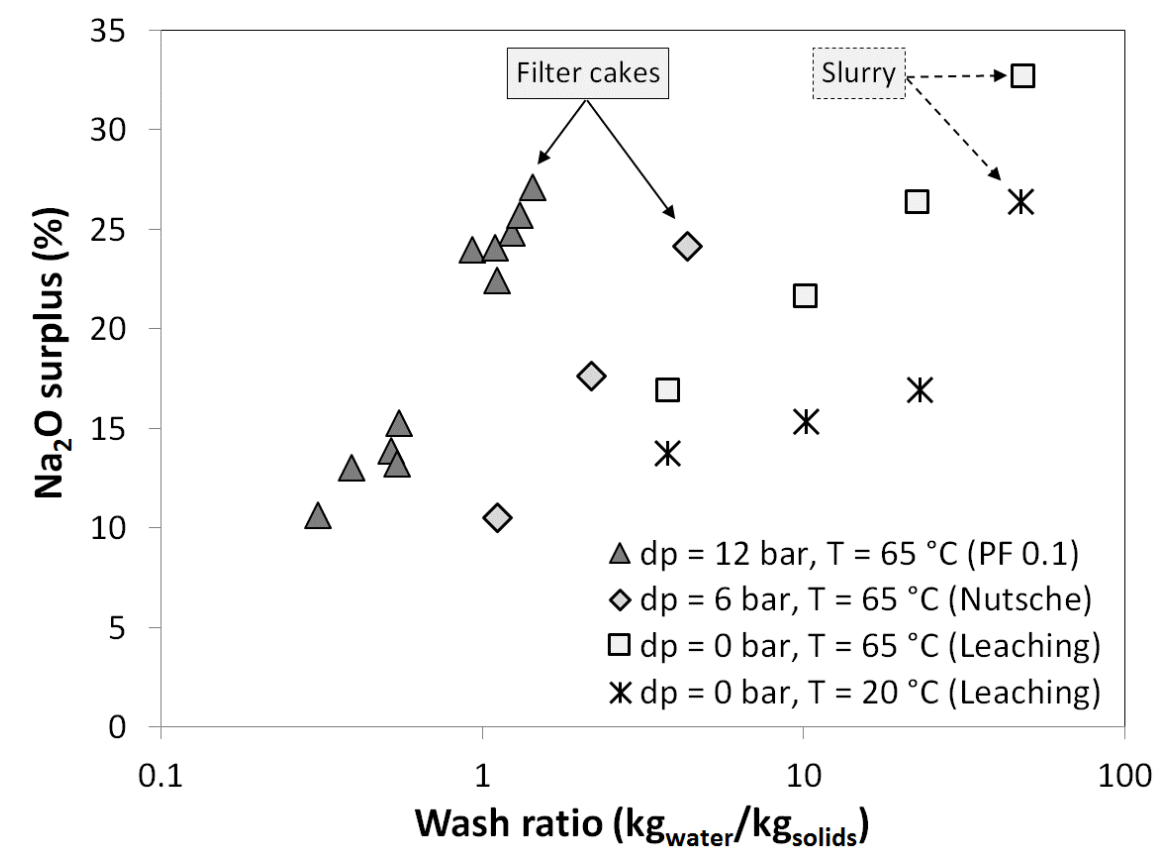

Fig. 2. Effect of wash ratio and pressure on the dissolution of alkali from the solid phase of bauxite residue filter cakes $\left(T=65^{\circ} \mathrm{C}\right)$ and effect of wash ratio and temperature on the dissolution of alkali from diluted bauxite residue slurry samples washed at different temperatures and pressures. The $\mathrm{Na}$ recovery surplus is defined in Eq. (3). Note the logarithmic scale of the x-axis. 
The washing of filter cakes in pressure filters is an operation which requires lots of experimental work to be even close to optimal. It is practically impossible to reach a complete removal of solutes from the cake, although displacement washing at high wash ratios may result in excellent washing efficiency. When bauxite residue filter cakes are washed with hot liquid in pressurized conditions, the results often look better than they actually are. There are solids in the cake which are dissolved due to the combination of elevated temperature and dilution, resulting in a decrease of the $\mathrm{pH}$ and ionic strength of the cake liquor. This phenomenon is explained in closer detail the Discussion section of the paper.

\subsection{Cake analyses: effect of liquid/solid (L/S) ratio}

The influence of the applied L/S ratio in the sample preparation step when the filter cake is mixed with water should not be underestimated, as the graphs in Fig. 3 clearly illustrate. Dilution of the sample with water causes an inevitable $\mathrm{pH}$ decrease, as the ionic strength of the liquid phase decreases, which in turn results in desorption and dissolution of suspended solids from the cake. In this case, the relative quantities of $\mathrm{Na}$ and $\mathrm{Al}$ originating from the solid phase were calculated on the basis of analysis results obtained by thermometric titration. As shown in Fig. 3a, the $\mathrm{pH}$ of the cake liquor decreased from 13.5 to 12.1 due to the dilution $(\mathrm{L} / \mathrm{S}$ ratio $=49)$ in 2 days, and the decrease of $\mathrm{pH}$ was at its steepest at lower $\mathrm{L} / \mathrm{S}$ ratios. The magnitude of the $\mathrm{pH}$ decrease is in agreement with previous results obtained for comparable bauxite residue slurries by the authors (Kinnarinen et al., 2015a). In the previous study, the slurry pH was reduced from 13.2 to 12.1 with a dilution factor of approximately 100 , and the $\mathrm{pH}$ was measured after 15 minutes sample stabilization time. Resulting from the decreasing $\mathrm{pH}$ (Fig. 3a), the $\mathrm{Na}_{2} \mathrm{O}$ and $\mathrm{Al}_{2} \mathrm{O}_{3}$ surplus (Fig. 3b, c) increased steeply at the lower $\mathrm{L} / \mathrm{S}$ ratios used in the sample preparation step, and more and more $\mathrm{Na}$ and $\mathrm{Al}$ were liberated from the solids until the highest L/S ratio 49 was reached.

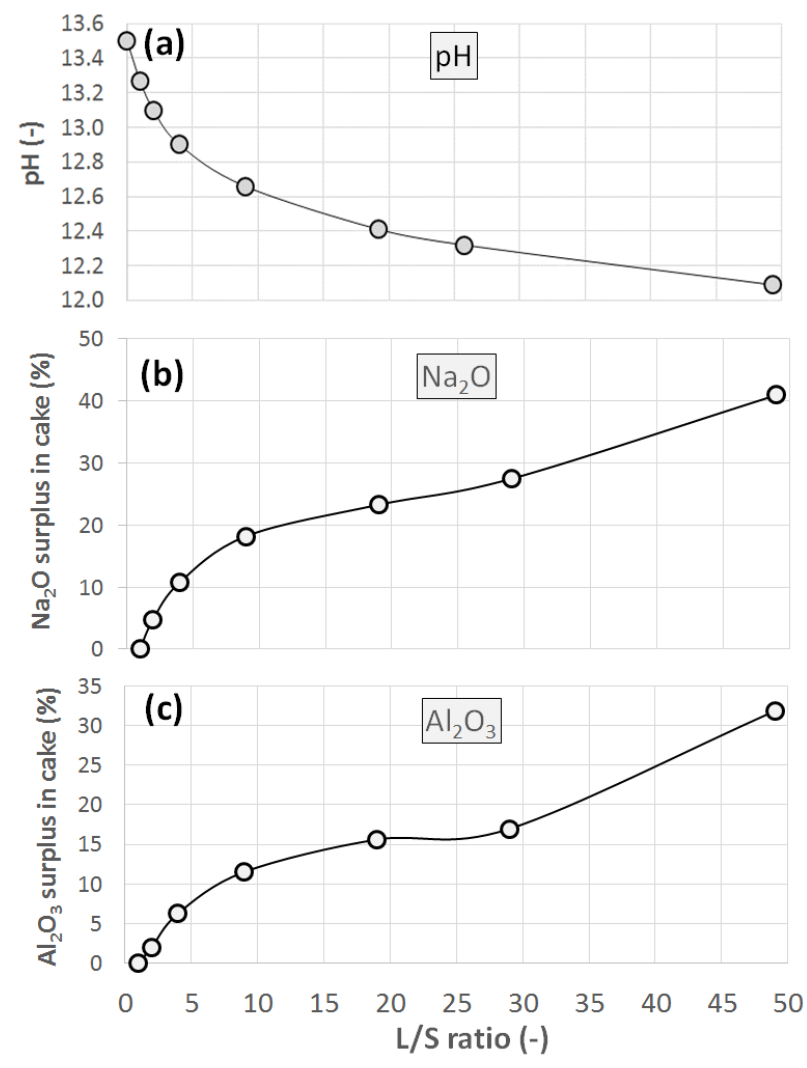


Fig. 3. $\mathrm{pH}$ curve illustrating the decrease of $\mathrm{pH}$ with increasing $\mathrm{L} / \mathrm{S}$ ratio (a) and the corresponding increase in the dissolution of $\mathrm{Na}_{2} \mathrm{O}$ (b) and $\mathrm{Al}_{2} \mathrm{O}_{3}$ (c) from bauxite residue filter cakes. The sample stabilization time before the analyses and $\mathrm{pH}$ measurements was 2 days.

\subsection{Cake analyses: effect of dilution liquid, temperature and time}

Water and aqueous sodium carbonate solutions were used as dilution liquids in order to study how the solute content and temperature of the dilution liquid would affect the measured total caustic contents of the filter cakes, expressed as $\mathrm{Na}_{2} \mathrm{CO}_{3}$. Fig. 4a illustrates the strong effect of temperature on the analysis results when the $\mathrm{Na}_{2} \mathrm{CO}_{3}$ concentrations were varied between zero and $77 \mathrm{~g} / \mathrm{kg}$ liquid. It is easy to see in Fig. $4 \mathrm{a}$ that the dilution liquids that have the highest concentrations of $\mathrm{Na}_{2} \mathrm{CO}_{3}$, have also the weakest response to temperature changes, which can be considered a positive feature regarding the avoidance of variation in the results of cake analyses.

Fig. $4 \mathrm{~b}$ shows the influence of the dilution time, i.e. the leaching time, on the analyzed $\mathrm{Na}_{2} \mathrm{CO}_{3}$ concentration in the cake for $\mathrm{L} / \mathrm{S}$ ratios 1 and 9 at $20^{\circ} \mathrm{C}$. The long dilution time of 2 days resulted in higher analyzed concentration of $\mathrm{Na}_{2} \mathrm{CO}_{3}$ in the cake, compared to the short dilution time $(75 \mathrm{~s}$ mixing + a few minutes for solid-liquid separation). The dilution time had a clear influence on the analysis result when the samples were prepared in water, but when the samples were prepared in a filtrate originating from the same slurry as the cake, and sampled from the filtration plant of the refinery at the same moment of time, the results became even more interesting, as shown in Fig. 4b. By comparing the short dilution with water with the short dilution with the filtrate $\left(45.8 \mathrm{~g}_{\mathrm{Na} 2 \mathrm{CO} 3} / \mathrm{kg}_{\text {filltrate }}\right)$, it can be observed that the analysis results give about doubled values for the dilution with water. This indicates that short dilution times should not be used at $20{ }^{\circ} \mathrm{C}$ with a dilution liquid containing large amounts of solutes, due to the slow release of caustic from the cake under such conditions.
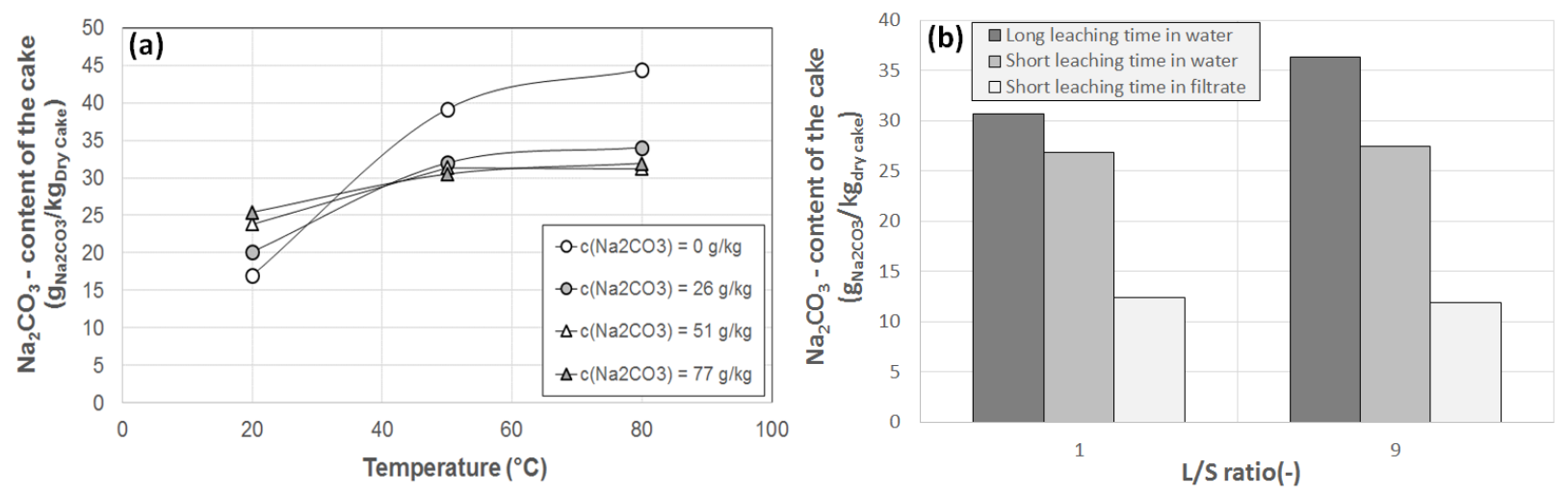

Fig. 4. Analysis results of filter cakes with respect to the sodium carbonate contents when the dilution liquid in the sample preparation stage was either pure water or a sodium carbonate solution with different concentrations and temperatures when the dilution time was $48 \mathrm{~h}$ (a), and the effect of leaching time at two L/S ratios (1 and 9) when the samples were diluted in water or filtrate by using long ( 2 days) and short (a few minutes) dilution times (b). All tests shown in Fig. $4 \mathrm{~b}$ were performed at $20{ }^{\circ} \mathrm{C}$.

\subsection{Calculation of solute recovery for filtration and cake washing operations}


The results of filtration and cake washing experiments with respect to the solute recovery depend on the definition of recovery. Solute recovery can be calculated on the basis of the filtrate and the feed (Eq. (1)), or on the basis of the mass of solute in the cake after the operation, compared to the mass of solute in the slurry fed into the filter unit (Eq. (2)). Fig. 5 presents a practical example of solute recovery calculations, showing clearly and consistently that calculation relying on the filtrate and feed concentrations yields a higher recovery, whereas using cake analysis $(\mathrm{L} / \mathrm{S}=9)$ in the calculation makes the recovery decrease by $10-20 \%$ in most cases.

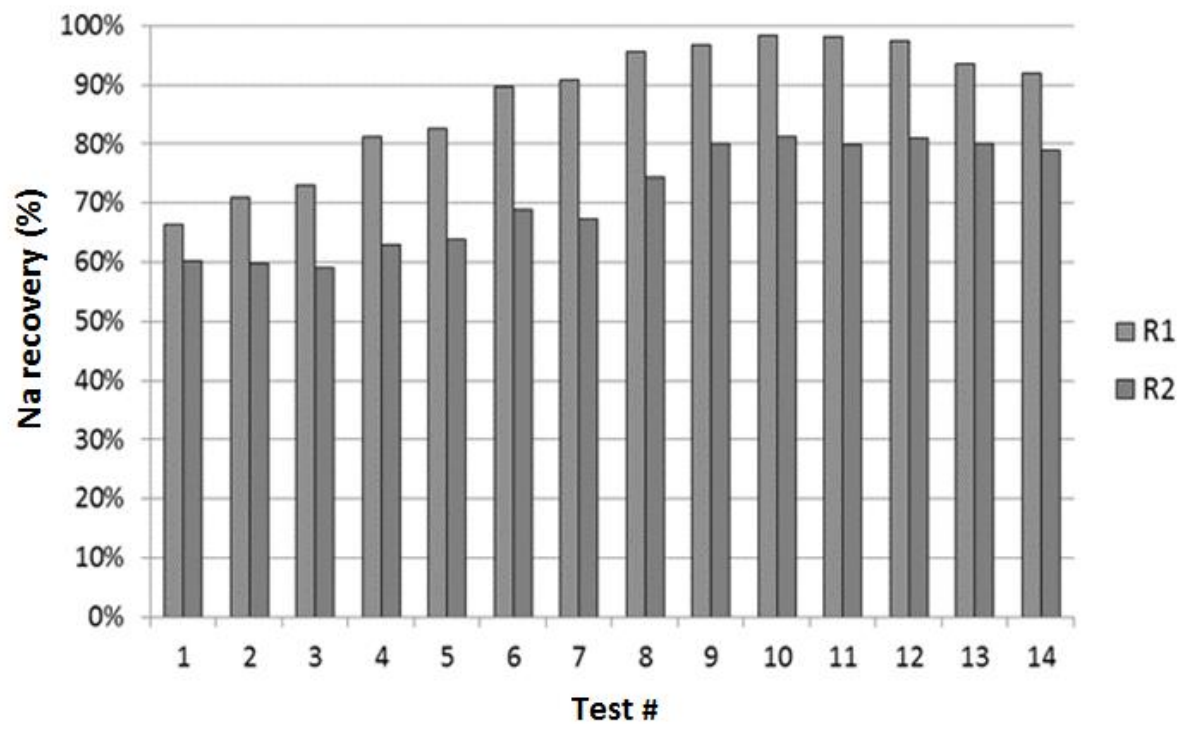

Fig. 5. Comparison of calculated solute recoveries R1and R2.

Which definition of solute recovery would then be the most relevant to be used as a new standard of solute recovery calculation? There is no universal answer to this question, due to the influence of the filtration and cake washing conditions ( $T, \Delta p$, wash ratio) on the filtrate and the cake. When solute recovery is calculated on the basis of filtrate and slurry, the value R1 becomes higher than it should in fact be, because pressure leaching of suspended solids occurs in the filter. On the other hand, the use of the result of cake analysis in the calculation, the leaching out of suspended solids from the cake results in a decreased recovery R2. The true solute recovery is thus apparently somewhere between R1 and R2.

\subsection{Remarks about particle size analyses}

Particle size measurement of bauxite residues, in particular bauxite residue filter cakes, is also complicated, due to the flocculation of solids in the counter current washing process at Bayer plants. Fig. 6 describes a situation where cake solids, and flocs formed from them, wetted for a long time prior to analysis to break the flocs prior to particle size measurements, were added into the particle dispersing unit of the analyzer, using water as the dispersing liquid. The solids concentration and the ionic strength of the liquid in the mixing unit were very low as usual, which had an impact on the particle size distribution of the flocculated material. As demonstrated in Fig. 6a with a washed filter cake, the reduction of the size of large flocs is clearly observable when the sample mixing time is increased. Similarly, the application of ultrasound in the sample dispersion system reduces the apparent particle size, which is clearest in the coarse end of the distribution (Fig. 6b). The shape of the distribution becomes different than in the case of mixing only, and the fraction of submicron particles increases, unlike in the case when ultrasonication is not used. 

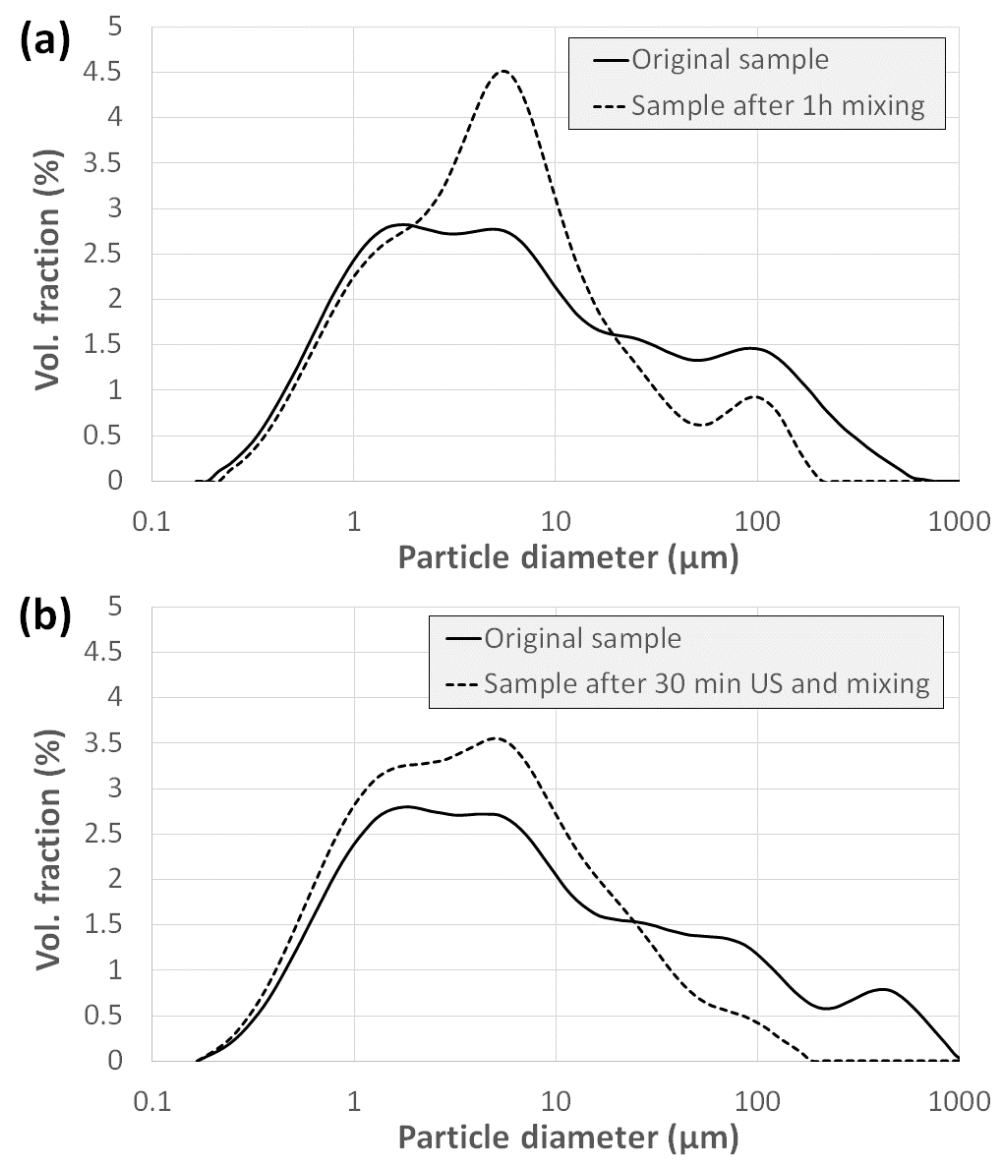

Fig. 6. Changes in the particle size distribution of washed bauxite residue filter cake when the sample has been kept under continuous agitation for $1 \mathrm{~h}$ (a), and under the influence of ultrasonication (US) in the same agitation conditions for $30 \mathrm{~min}(\mathrm{~b})$.

\section{Discussion}

The key findings presented in this paper can be summarized in a few bullet points:

- The conditions in pressure filters leach lots of extra sodium aluminate out of the cake. Leaching equal amounts of the same components out of the slurry solids at ambient pressure requires over 10 times higher wash ratios. A more complete study on the effect of wash water temperature and pressure should be performed with different bauxite residue samples in the future.

- The leaching of caustic and alumina out of filter cakes in the sample preparation stage increases with the L/S ratio. No end to leaching was observed when the L/S ratio was gradually increased to 49 .

- The composition of the dilution liquid has also an influence on the leaching of suspended solids from the cake. Water dissolves more material than $\mathrm{Na}_{2} \mathrm{CO}_{3}$ solutions. On the other hand, sample preparation can be performed more reliably with water when the sample stabilization time is short.

- There is a need for the development of a standard method for cake analysis and solute recovery calculations for investigations where the mass balance calculations are performed considering the 
filtration plant only. When the whole plant is considered, the changes in the caustic inventory should be in agreement with the $\mathrm{Na}_{2} \mathrm{O}$ loss with the cake.

- Additionally, the measurement of particle size distribution should be performed according to the same procedure, by using long sample dilution time, strong mixing and ultrasonication, because the size distributions vary depending e.g. on the particle dispersing conditions.

According to the existing literature, the main reason for the increased leaching from the solid phase is desorption and/or dissolution of desilication products (DSP). The phenomenon was observed for almost two decades ago by Thornber and Binet (1999), who found that desorption of suspended solids increased when bauxite residue was washed with water in four successive stages. Thornber and Binet concluded that the release of sodium, hydroxyl, carbonate and aluminate ions was largely due to the presence of DSP, calcium species, and minerals having charged species on their surfaces. Chvedov et al. (2011) also refer to the importance of silica-containing precipitates which originate from the Bayer process and are deposited on the particle surfaces. They report those silica-containing compounds to be the main source of hydroxyl groups in bauxite residue solids. According to an extensive review by Gräfe et al. (2009), the surface charge of such desilication products is negative. The buffering capacities of bauxite residues have been reported to be closely related to the presence of alkaline solids, such as sodalite (present in DSP) and calcite (Snars and Gilkes, 2009).

The $\mathrm{pH}$ decrease caused by dilution correlates well with the dissolution of $\mathrm{Na}, \mathrm{Al}$ and caustic. The solid phase of a well washed and deliquored filter cake has an especially strong tendency to dissolve in the sample preparation stage. This is due to the low residual caustic content of such a cake, which consequently means that the cake does not have the buffering capacity required to persist the $\mathrm{pH}$ decrease.

Many metals present in bauxite residues have low solubility, unless acid is used to adjust the $\mathrm{pH}$ to the acidic range. Metals such as $\mathrm{Na}, \mathrm{Ca}, \mathrm{Mg}, \mathrm{Fe}, \mathrm{Cu}, \mathrm{Al}, \mathrm{Mn}, \mathrm{Ti}$ and $\mathrm{Cr}$ are increasingly leached out from the material with a decreasing $\mathrm{pH}$ (Rubinos and Barral, 2013). Although Rubinos and Barral report results for $\mathrm{pH}$ values below 10, it is apparent from their data as well that the elements present in the desilication products, i.e. $\mathrm{Al}, \mathrm{Na}$ and $\mathrm{Si}$, are sensitive to $\mathrm{pH}$ changes also in the basic conditions.

Khaitan et al. (2009) investigated the effect of acid titration time on the acid consumption of the titration procedure. They observed that tens of days may be required to reach the state of a constant $\mathrm{pH}$, and the required time apparently depends on the end $\mathrm{pH}$ of the titration.

Additionally, solid reaction products resulting from lime addition in the Bayer process may have an influence on the cake analyses. Kirwan et al. (2013) summarize earlier literature on the topic and mention calcium hydroxides, carbonates and aluminates, for instance tricalcium aluminate, as buffering species.

As regards the changes in the particle size distribution when bauxite residue solids are dispersed and kept mixed in water, it is obvious that the breakage of flocs plays a major role, the dissolution of particles being less important.

\section{Conclusions}

The aim of this paper was to present some selected results of the authors' experimental work performed with various filter cakes during the past years. All bauxite residue filter cakes have been observed to have a more or less similar behavior in the sample preparation stage prior to chemical analyses: dilution with a large amount of water makes the solute content look higher than it actually is, due to partial dissolution of the suspended solids content. When the L/S ratio used in order to re-slurry the cake for analysis has been 
increased from 1 to about 50, the dissolution of $\mathrm{Na}$ has been observed to increase by over $40 \%$ and that of $\mathrm{Al}$ by over $30 \%$. This result depends on the refinery and the fraction of desilication products in the cake. On the other hand, the dissolution of surplus $\mathrm{Na}$ and $\mathrm{Al}$ can be prevented by diluting the cake samples with a filtrate collected from the same experiment. Increasing the pressure and temperature will inevitably increase the leaching of $\mathrm{Na}$ and $\mathrm{Al}$ from the solids. The most important factor having an influence on these dissolution phenomena is the decreasing $\mathrm{pH}$ of the liquid. However, a short dilution time prior to liquid analysis should not be used, because reaching the equilibrium between the solids and liquid phases may take a long time, which makes the differences between the samples become larger when the cake sample is prepared promptly. Temperature has a strong effect on the dissolution of solutes, especially when water is used as the dilution liquid, but this factor is not likely to cause significant variation in the analysis results in cases where the samples can be prepared at a constant room temperature.

\section{References}

Bott, R., Langeloh, T., 2015. Process options for the filtration and washing of bauxite residue. Bauxite Residue Valorisation and Best Practices Conference, Leuven, Belgium, 5.-7.10.2015.

Chvedov, D., Ostap, S., Le, T., 2001. Surface properties of red mud particles from potentiometric titration. Colloids Surf. A 182, 131-141.

Clark, M.W., Johnston, M., Reichelt-Brushett, A.J., 2015. Comparison of several different neutralisations to a bauxite refinery residue: Potential effectiveness environmental ameliorants. Appl. Geochem. 56, 1-10.

Deng, B., Li, G., Luo, J., Ye, Q., Liu, M., Peng, Z., Jiang, T., 2017. Enrichment of $\mathrm{Sc}_{2} \mathrm{O}_{3}$ and $\mathrm{TiO}_{2}$ from bauxite ore residues. J. Hazard. Mater. 331, 71-80.

Ghosh, I., Guha, S., Balasubramaniam, R., Kumar, A.V.R., 2011. Leaching of metals from fresh and sintered red mud. J. Hazard. Mater. 185, 662-668.

Gräfe, M., Power, G., Klauber, C., 2009. Review of bauxite residue alkalinity and associated chemistry. CSIRO Document DMR-3610, May 2009.

Gräfe, M., Power, G., Klauber, C., 2011. Bauxite residue issues: III. Alkalinity and associated chemistry. Hydrometallurgy 108, 60-79.

Johnston, M., Clark, M.W., McMahon, P., Ward, N., 2010. Alkalinity conversion of bauxite refinery residues by neutralization. J. Hazard. Mater. 182, 710-715.

Khaitan, S., Dzombak, D.A., Lowry, G.V., 2009. Chemistry of the acid neutralization capacity of bauxite residue. Environ. Eng. Sci. 26(5), 873-880.

Kinnarinen, T., Holliday, L., Häkkinen, A., 2015a. Dissolution of sodium, aluminum and caustic compounds from bauxite residues. Miner. Eng. 79, 143-151.

Kinnarinen, T., Lubieniecki, B., Holliday, L., Helsto, J.-J., Häkkinen, A., 2015b. Enabling safe dry cake disposal of bauxite residue by deliquoring and washing with a membrane filter press. Waste Manage. Res. 33(3), 258-266.

Kinnarinen, T., Lubieniecki, B., Holliday, L., Helsto, J.-J., Häkkinen, A., 2015c. Recovery of sodium from bauxite residue by pressure filtration and cake washing. Int. J. Miner. Process. 141, 20-26. 
Kirwan, L.J., Hartshorn, A., McMonagle, J.B., Fleming, L., Funnell, D., 2013. Chemistry of bauxite residue neutralization and aspects to implementation. Int. J. Miner. Process. 119, 40-50.

Kong, X., Li, M., Xue, S., Hartley, W., Chen, C., Wu, C., Li, X., Li, Y., 2017. Acid transformation of bauxite residue: Conversion of its alkaline characteristics. J. Hazard. Mater. 324, 382-390.

Liu, Z., Li, H., 2015. Metallurgical process for valuable elements recovery from red mud - A review. Hydrometallurgy 155, 29-43.

Luo, M., Qi, X., Zhang, Y., Ren, Y., Tong, J., Chen, Z., Hou, Y., Yeerkebai, N., Wang, H., Feng, S., Li, F., 2016. Study on dealkalization and settling performance of red mud. Environ. Sci. Pollut. Res. 24(2), 17941802.

Power, G., Gräfe, M., Klauber, C., 2011. Bauxite residue issues: I. Current management, disposal and storage practices. Hydrometallurgy 108, 33-45.

Rubinos, D.A., Barral, M.T., 2013. Fractionation and mobility of metals in bauxite red mud. Environ. Sci. Pollut. Res. 20, 7787-7802.

Snars, K., Gilkes, R.J., 2009. Evaluation of bauxite residues (red muds) of different origins for environmental applications. Appl. Clay Sci. 46, 13-20.

Thornber, M.R., Binet, D., 1999. Caustic soda adsorption on Bayer residues. In: Worsley (Ed.), Alumina, 5th International Alumina Quality Workshop, AQW Inc., Bunbury, pp. 498-507.

World Aluminium. http://www.world-aluminium.org/statistics/alumina-production/ 